\title{
IMPLANTAÇÃO DA COLETA SELETIVA EM UM CONDOMÍNIO RESIDENCIAL EM CAMPOS DOS GOYTACAZES- RJ
}

\author{
Lívia Pita Correa - livia.pita.correa@gmail.com \\ IFF - campus, Campos Guarus \\ Nayara Felix Barreto - nanafbarreto@gmail.com \\ IFF - campus, Campos Guarus \\ Yandressa Karine Rodrigues de Pinho - yandressa@ hotmail.com \\ IFF - campus, Campos Guarus \\ Vitor Nunes Guimarães - vgn9@ hotmail.com \\ IFF - campus, Campos Guarus \\ Laíne Ingnácio Hespanhol - lainehespanhol@gmail.com \\ IFF - campus, Campos Guarus \\ Raiane de Oliveira Machado - raianemachado18@ gmail.com \\ IFF - campus, Campos Guarus \\ Laureana Aparecida Coimbra Pelegrini - laureanapelegrini@yahoo.com.br \\ IFF - campus, Campos Guarus
}




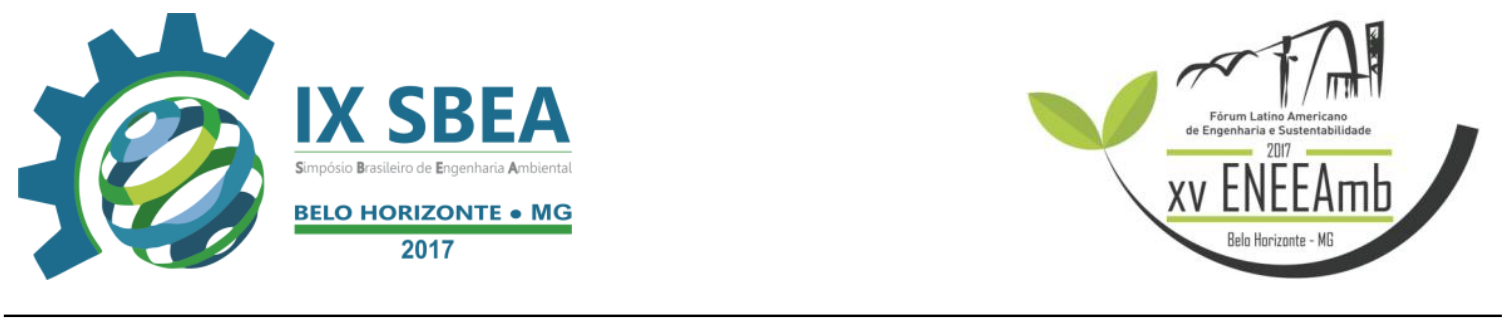

\section{RESUMO}

O presente trabalho foi desenvolvido no Edifício Sunset Park, localizado na cidade de Campos dos Goytacazes/RJ e tem como objeto de fazer um trabalho de educação ambiental com os condôminos, implantar a coleta seletiva e verificar o comportamento dos moradores em relação a coleta seletiva. A Lei $\mathrm{n}^{\mathrm{o}}$ 12.305/10 instituiu a Política Nacional de Resíduos Sólidos (PNRS) que fornece as diretrizes relativas à gestão integrada e ao gerenciamento de resíduos sólidos e também destaca as responsabilidades dos geradores e do poder público. A coleta seletiva e a reciclagem são consideradas práticas necessárias e importantes, pois são capazes de promover mudança comportamental gerando benefícios ambientais.

Palavras-chave: Coleta seletiva, reciclagem, educação ambiental.

\section{INTRODUÇÃO/OBJETIVO}

A geração de resíduos sólidos urbanos tem aumentado cada vez mais, o crescimento da população mundial e principalmente o crescimento urbano desordenado são fatores que colaboram diretamente para esse aumento na geração de resíduos.

Atualmente enfrenta-se vários problemas ambientais causados pela geração e destinação inadequada dos resíduos sólidos gerados nas cidades. Segundo Grippi (2006,p.5), cada brasileiro gera em média 500 g de lixo por dia, ou seja, algo em torno de 100000 t por dia de lixo gerado em todo o país.

Segundo o Instituto de Pesquisa Econômica Aplicada (2012), são coletadas 183,5 mil toneladas de resíduos sólidos por dia no Brasil, em 90\% do total de domicílios, o que representa $98 \%$ das moradias urbanas. A matéria orgânica representa 51,4\% do lixo diário, e apenas $31,9 \%$ é composto de material reciclável.

Preocupado com a gestão de resíduos sólidos o Brasil, em Agosto de 2010, estabeleceu a Política Nacional de Resíduos Sólidos (PNRS) que em seu artigo $7^{\circ}$ resume seus objetivos: “a não geração, redução, reutilização, reciclagem e o tratamento dos resíduos sólidos, bem como disposição final ambientalmente adequada dos rejeitos". Também destaca o papel da educação ambiental como instrumento para promover a preservação ambiental e o desenvolvimento sustentável. 


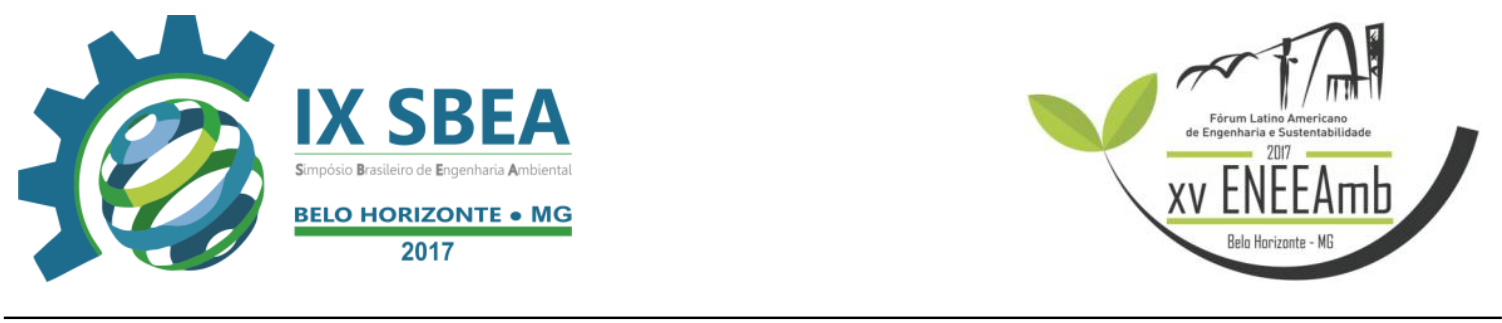

A coleta seletiva e a reciclagem são consideradas partes da mudança comportamental frente a eliminação dos resíduos produzidos pelo humano e a educação ambiental é a ferramenta que proporciona sensibilidade na comunidade alvo favorecendo a prática da coleta seletiva e da reciclagem. O objetivo do presente trabalho é fazer um trabalho de educação ambiental com os condôminos do Sunset Park localizado no município de Campos dos Goytacazes/RJ, implantar a coleta seletiva e verificar o comportamento dos moradores em relação a coleta seletiva.

\section{METODOLOGIA}

A presente pesquisa foi realizada por alunos do curso de Bacharel em Engenharia Ambiental do Instituto Federal Fluminense, campus Campos-Guarus. O condomínio Sunset Park foi escolhido para esta pesquisa, devido ao fato de alguns dos alunos pesquisadores residirem no local e no mesmo não haver um sistema de coleta seletiva.

O Sunset Park possui oito andares e vinte e dois apartamentos por andar. Todos os apartamentos encontram-se ocupados, aproximadamente $47 \%$ dos apartamentos são alugados, mas a rotatividade de locação é alta devido sua localização privilegiada, na principal avenida da cidade, próximo ao centro comercial, próximo das principais faculdades e principais vias de acesso a estrada Federal (BR 101).

Para realizar essa pesquisa, primeiramente foi elaborado um questionário contendo onze perguntas fechadas. As perguntas eram sobre informações pessoais do participante, sobre o descarte de resíduos sólidos e coleta seletiva no condomínio. Esse questionário foi colocado nas caixas de correio de todos os apartamentos do prédio. A primeira parte continha uma breve explicação sobre a pesquisa, introduções de como responder o questionário e um pedido para que depois de concluído o mesmo fosse entregue ao porteiro.

Com o intuito de mobilizar os moradores no prédio a participarem da pesquisa, foi feita uma campanha de conscientização com distribuição de folhetos explicativos sobre o descarte inadequado de resíduos e uma breve explicação de possíveis soluções, também sobre a importância da coleta seletiva. Foram fixados cartazes ilustrativos nos elevadores e portarias. 


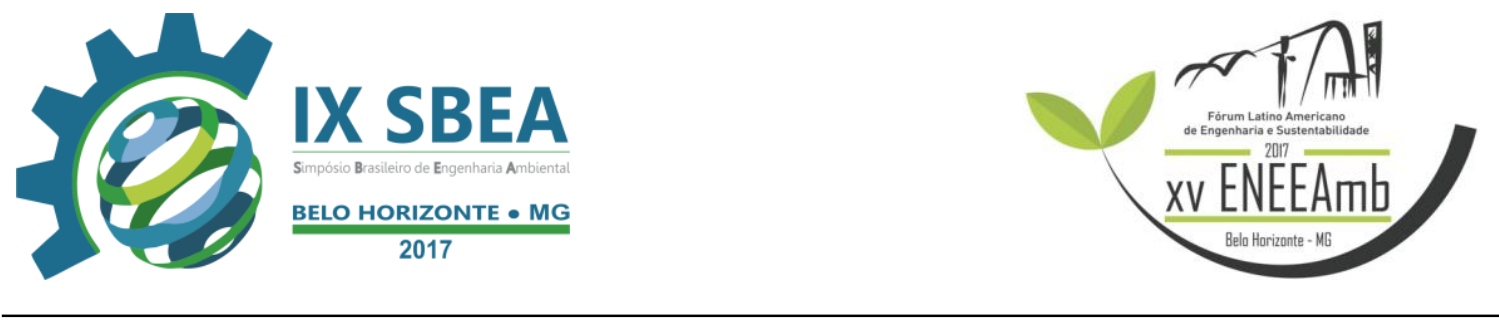

Após, um período de quatro semanas foram entregues ao porteiro um total de 58 questionários respondidos, os dados foram tabulados e a coleta seletiva foi implantada. Após a implantação foi feito um monitoramento da participação dos moradores através da pesagem dos resíduos descartados para coleta seletiva.

\section{ESULTADOS/ DISCUSSÃO}

Após o trabalho de educação ambiental os questionários respondidos por 58 moradores foram tabulados. Analisando a tabela 1, pode-se dizer que $53 \%$ dos respondentes foram mulheres, $23 \%$ tem idade entre 20 e 30 anos e $26 \%$ tem idade entre 31 e 40 anos e $31 \%$ tem o $3^{\circ}$ grau completo.

\begin{tabular}{|c|c|c|}
\hline Variável & Nível da variável & Respondentes \\
\hline \multirow[t]{2}{*}{ Sexo } & Homens & $47 \%$ \\
\hline & Mulheres & $53 \%$ \\
\hline \multirow[t]{6}{*}{ Idade } & Menos de 20 anos & $2 \%$ \\
\hline & De 20 a 30 anos & $26 \%$ \\
\hline & De 31 a 40 anos & $26 \%$ \\
\hline & De 41 a 50 anos & $14 \%$ \\
\hline & De 51 a 60 anos & $9 \%$ \\
\hline & Mais de 61 anos & $24 \%$ \\
\hline \multirow[t]{7}{*}{ Escolaridade } & $1^{\circ} \mathrm{Grau}$ incompleto & $2 \%$ \\
\hline & $1^{\circ} \mathrm{Grau}$ completo & $2 \%$ \\
\hline & $2^{\circ}$ Grau incompleto & $19 \%$ \\
\hline & $2^{\circ}$ Grau completo & $2 \%$ \\
\hline & $3^{\circ}$ Grau incompleto & $31 \%$ \\
\hline & $3^{\circ}$ Grau completo & $29 \%$ \\
\hline & Pós-Graduação & $16 \%$ \\
\hline
\end{tabular}

Tabela 1- Perfil dos respondentes relacionados ao sexo, idade e escolaridade.

Ainda sobre o questionário, foi perguntado quantas pessoas moravam em cada apartamento, assim como mostra a figura 1, 49\% dos apartamentos moram uma pessoa, $37 \%$ dos apartamentos moram duas pessoas, $11 \%$ dos apartamentos moram 3 pessoas, $2 \%$ moram 4 pessoas e $2 \%$ moram 5 pessoas. Acredita-se que esses fatos se devem ao fato do Sunset Park possuir vários apartamentos de apenas um quarto. 

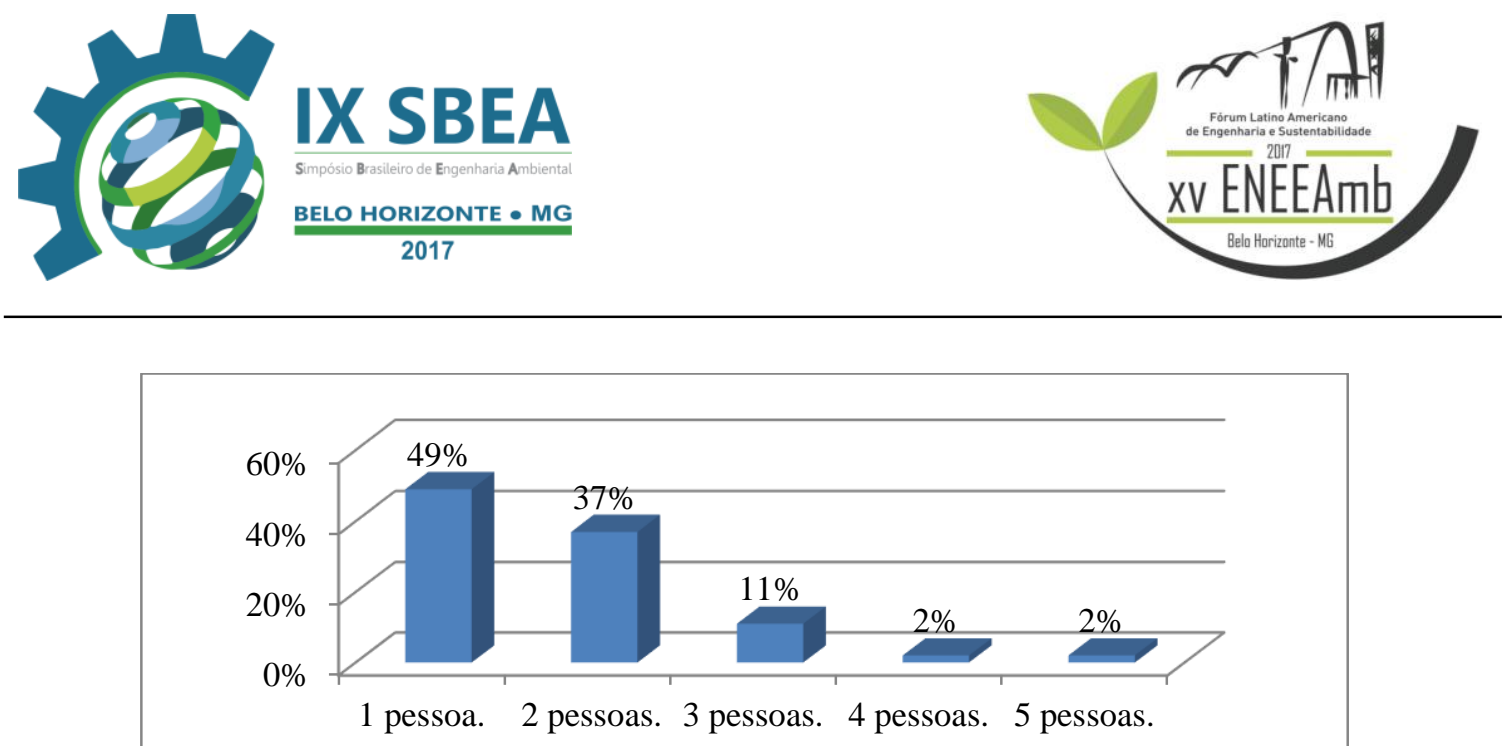

Figura 1: Número de pessoas que mora em cada apartamento.

A maior parte dos participantes $95 \%$, afirmou saber o que é coleta seletiva, mas $71 \%$ afirmou não saber qual a destinação do lixo que é coletado diariamente no condomínio, $81 \%$ disse saber o que são resíduos perigosos. Acredita-se que esses resultados revelam que o trabalho de educação ambiental realizado durante o presente trabalho pode ter colaborado para o esclarecimento de algumas questões referentes ao assunto.

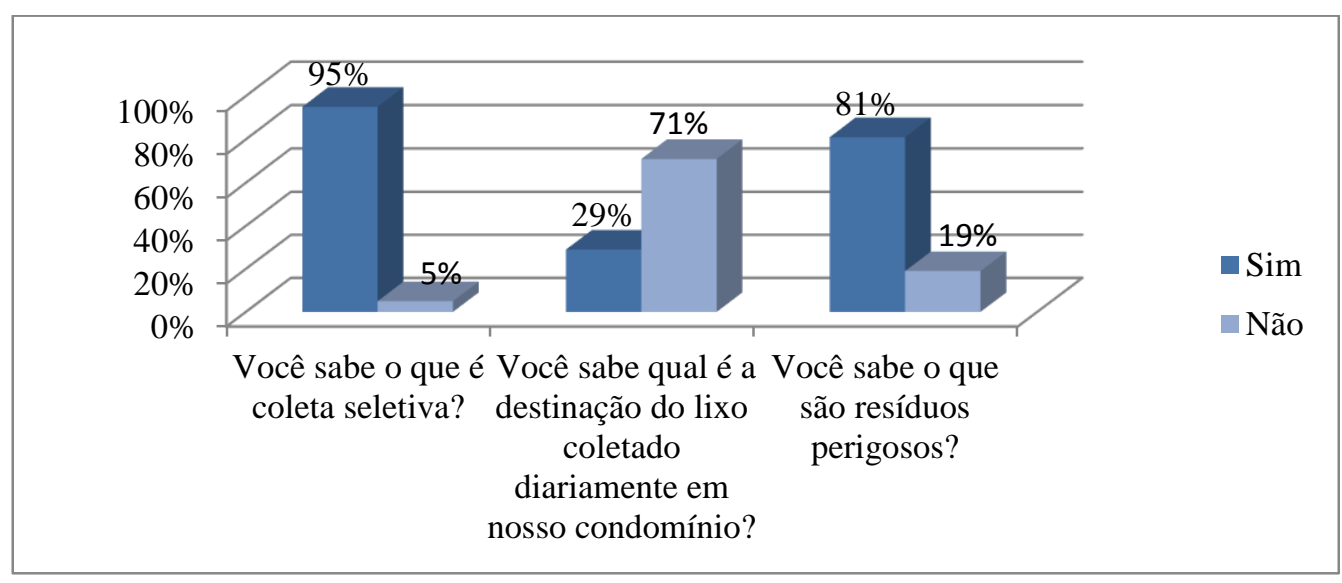

Figura 2: Conhecimento sobre resíduos sólidos.

Conforme a figura 3, apenas $47 \%$ dos participantes afirmaram não separar o lixo orgânico do lixo reciclável, mostrando que as pessoas do condomínio apesar de demostrarem conhecimento sobre a coleta seletiva como mostra na figura 2, elas não tem a prática de separar o lixo. 34\% afirmam separar o lixo, $9 \%$ diz que falta tempo e $10 \%$ diz separar às vezes. 


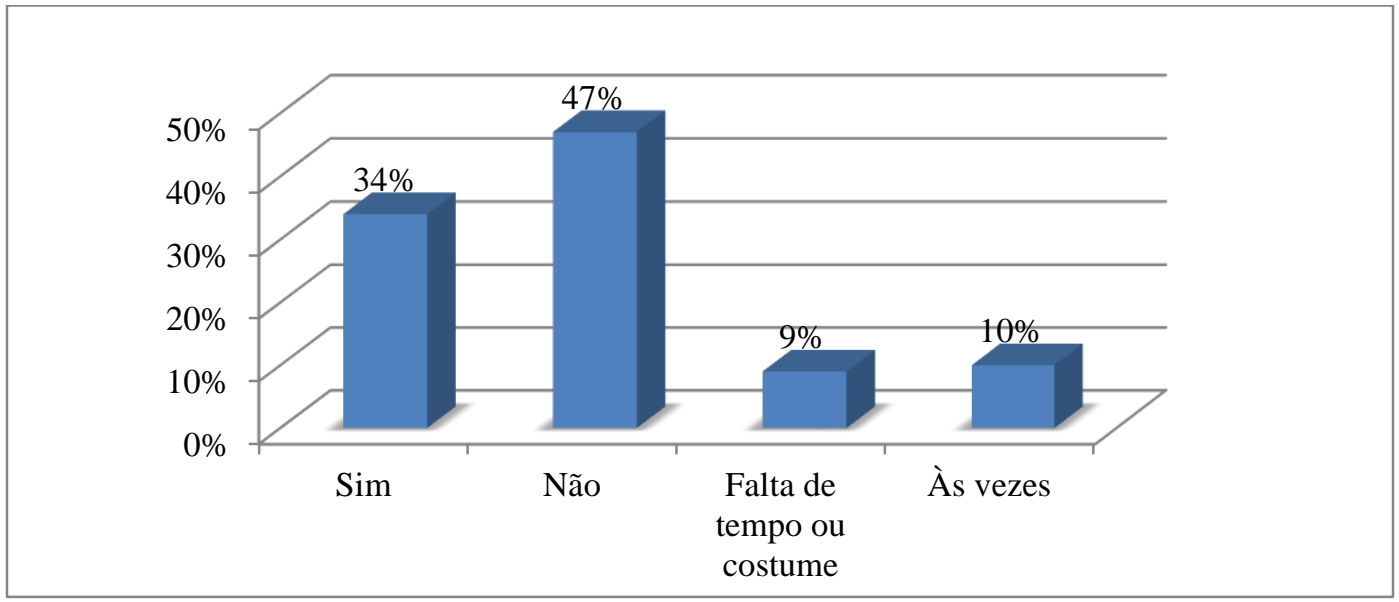

Figura 3: Você costuma separar o "lixo" orgânico (restos de comida em geral, cascas de ovos, etc.) do "lixo" reciclável (plásticos, metais, papel, vidros, etc.)?

$\mathrm{Na}$ figura 4, é possível perceber que $62 \%$ das pessoas afirmaram descartar resíduos perigos em local apropriado, um número um pouco baixo comparado aos dados da figura 2 , onde $81 \%$ dos respondentes afirmam saber o que são resíduos perigosos. $\mathrm{O}$ que nos mostra que apesar de boa parte das pessoas do condomínio saber o que são resíduos perigosos, não os descartam em local apropriado. $31 \%$ não descartam o lixo perigoso em local apropriado, e 7\% dos respondentes às vezes descartam em local apropriando.



Figura 4: Como você descarta o "lixo" perigoso, como pilhas e baterias, lâmpadas e restos de tintas?

Em sua maioria $100 \%$ dos moradores afirmaram tratar de uma boa ideia a implantação da coleta seletiva no condomínio. 

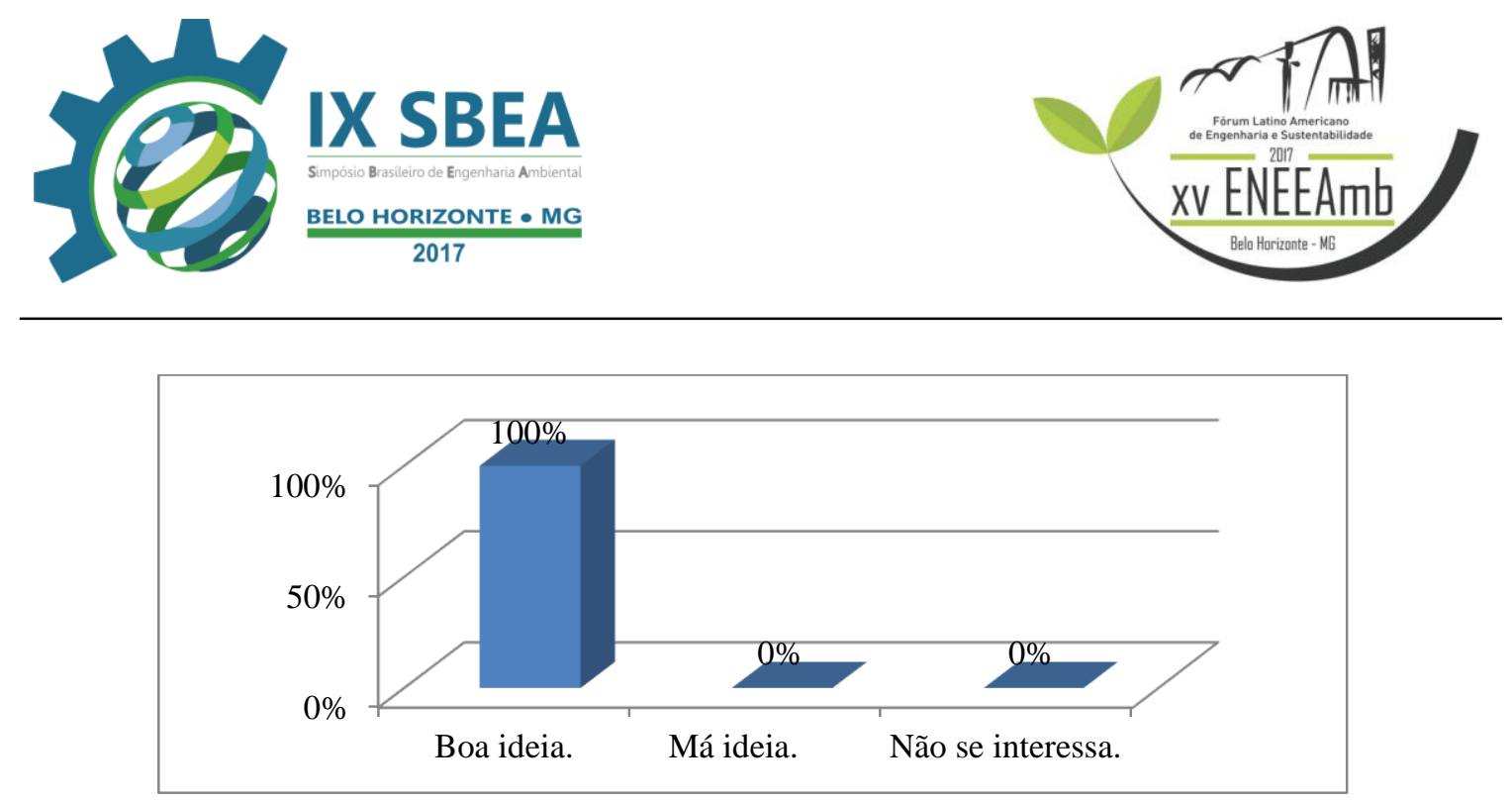

Figura 5: O que você acha da proposta de implantação da coleta seletiva no condomínio?

Com o intuito de tentar melhorar a logística para juntar o lixo reciclável do condomínio, sem precisar de muito esforço dos funcionários, foi implantado um único ponto de coleta, que diferente do lixo não reciclável existe dois em cada andar do prédio. Então esse ponto de coleta do lixo reciclável foi implantado no térreo porque é um local onde todos os moradores passam diariamente. Na figura 6 pode-se verificar que nem todos os participantes se dispuseram a depositar o lixo reciclável no local adequado, (um total de $3 \%)$.

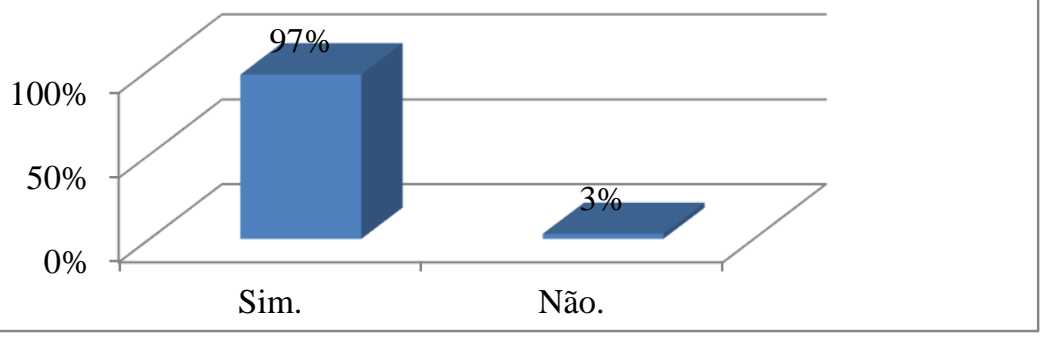

Figura 6: Você se dispõe a descartar o lixo reciclável no ponto de coleta (no térreo)?

Após implantação a coleta seletiva, os resíduos começaram a ser pesados logo na primeira semana, a pesagem foi feita semanalmente durante treze semanas. O caminhão da coleta seletiva passava toda terça feira de manhã e por isso a pesagem acontecia toda a segunda feira à noite.

Analisando a figura 7, é possível perceber que nas quatro primeiras semanas da pesagem do lixo, o volume de resíduo reciclável maior, tendo um pico na quarta semana 




que corresponde ao peso de 47,41 Kg. Logo após o pico da quarta semana houve uma queda no peso verificado na quinta semana, que corresponde a $14,89 \mathrm{~kg}$, esse valor vai abaixando até a sétima semana, que é o valor mais baixo do gráfico que corresponde a $6,51 \mathrm{Kg}$. Depois dessa baixa muito grande, houve um aumento no peso, que da nona a décima terceira semana foi mantendo uma média de $15,1 \mathrm{Kg}$.

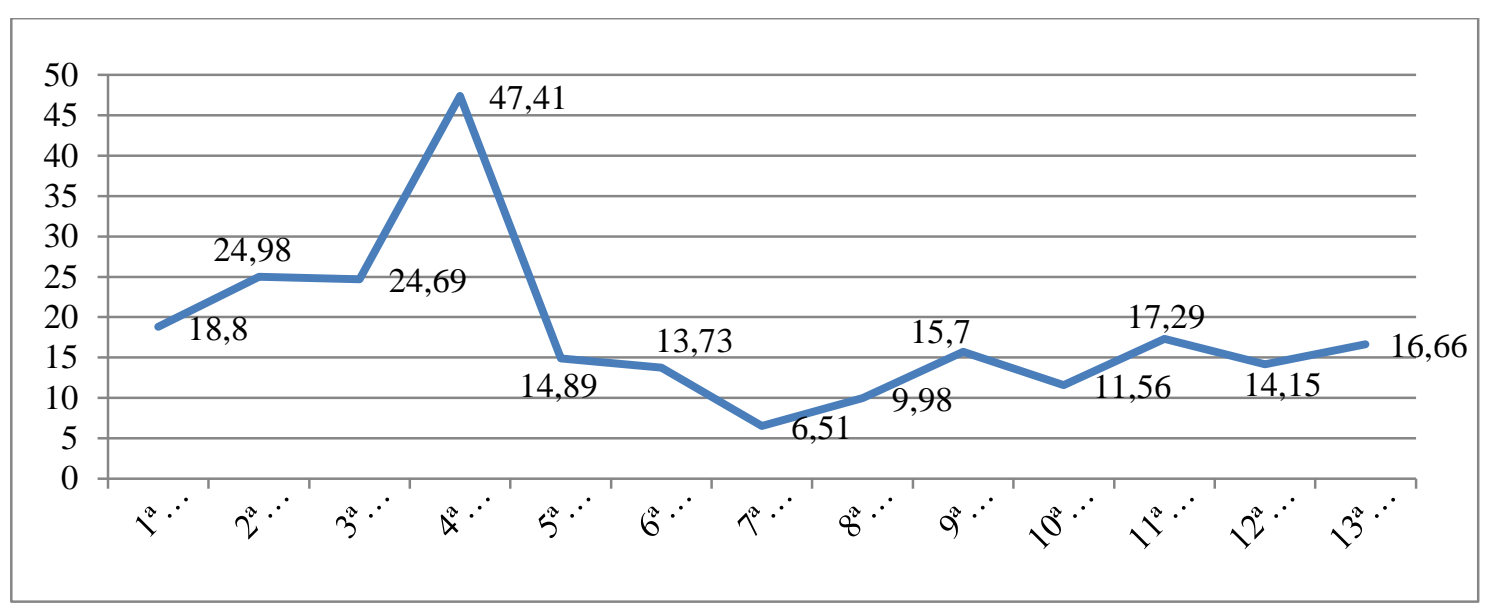

Figura 7: Pesagem do lixo reciclável semanalmente em Kg.

Os resultados da figura 7 revelam que no início houve uma expressiva adesão dos moradores no que se refere a coleta seletiva, mas com o tempo a participação se tornou menor, fato que revela a necessidade um trabalho de educação ambiental e conscientização mais eficiente que motive os moradores a colaborarem constantemente.

\section{CONCLUSÕES/RECOMENDAÇÕES}

Baseando-se nos dados apontados como resultados é possível concluir que a implantação da coleta seletiva no Sunset Park era necessária e funcionou de forma mais eficiente nas quatro primeiras semanas tendo uma queda da participação dos moradores nas semanas que se seguiram fato que demonstra que a educação ambiental possui um papel fundamental na implantação da coleta seletiva e na conscientização dos moradores para a necessidade de descartar os resíduos sólidos de maneira adequada. 


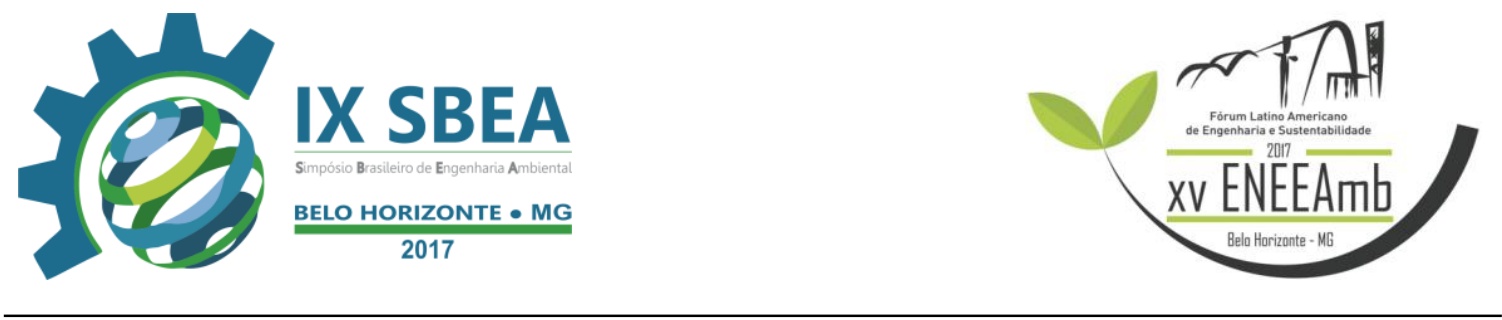

\section{REFERÊNCIAS BIBLIOGRÁFICAS}

. Diagnóstico do manejo de resíduos sólidos urbanos-2004. Programa de Modernização do Setor Saneamento. Sistema Nacional de Informações sobre Saneamento: Brasília: Ministério das Cidades, 2006.

O mecanismo de desenvolvimento limpo nos empreendimentos de manejo de resíduos sólidos urbanos e o impacto do Projeto de Lei no 5296/2005. Brasília: Ministério das Cidades, 2006. (Saneamento para todos, n. 3).

Resolução nº 001, de 23 de janeiro de 1986. Diretrizes gerais para uso e implementação da avaliação do impacto ambiental como um dos instrumentos da Política Nacional do Meio Ambiente (EIA e RIMA). Disponível em: . Acesso em: 08 ago. 2008.

Resolução n ${ }^{\circ} 358$, de 29 de abril de 2005. O tratamento e a disposição final dos serviços de saúde. Disponível em: . Acesso em: 08 ago. 2008.

ASSOCIAÇÃO BRASILEIRA DE NORMAS TÉCNICAS (ABNT). NBR - 10.004: Resíduos Sólidos - Classificação. Rio de Janeiro, 2004.

BRASIL. Lei nọ 9.795, de 27 de abril de 1999. Política Nacional de Educação Ambiental. Disponível em: . Acesso em: 4 ago. 2008.

BRASIL. Secretaria Nacional de Saneamento Ambiental. Dados do Brasil para a primeira avaliação regional 2002 dos serviços de manejo de resíduos sólidos municipais nos países da América Latina e Caribe. Brasília: OPAS/OMS, 2003.

CAMPOS DOS GOYTACAZES/RJ. PREFEITURA MUNICIPAL. Campos dos Goytacazes: perfil 2005/Prefeitura Municipal de Campos dos Goytacazes, Institutos Superiores de Ensino do CENSA, FUNDENOR. Campos dos Goytacazes, 2006.

D`ALMEIDA, M. L. O.; VILHENA A. Lixo municipal: manual de gerenciamento integrado. 2. ed. São Paulo: IPT; CEMPRE, 2000. (Publicação IPT, 2622)

DE DESENVOLVIMENTO ECONÔMICO. BNDES, um banco de idéias: 50 anos refletindo o Brasil. Rio de Janeiro, 2002. p. 273-289.

DIAS, G. F. Educação Ambiental: princípios e práticas. 9. ed. São Paulo: Gaia, 2004, 551 p.

GESTÃO integrada de resíduos sólidos na Amazônia. Rio de Janeiro: IBAM; MMA/SQA, 2001. 
GODINHO, Rui M. C. O Sistema de gestão integrada de resíduos sólidos urbanos da área metropolitana de Lisboa: um projecto sustentável com futuro. Trabalho apresentado no Seminário Internacional NUTAU 2004: demandas sociais, inovações tecnológicas e a cidade, São Paulo, 2004.

GOMES, Maria Stella Magalhães (Coord.). Lixo e cidadania: guia de ações e programas para a gestão de resíduos sólidos. Brasília : Ministério das Cidades, 2005. GRIMBERG, E.; BLAUTH, P. Coleta seletiva, reciclando materiais, reciclando valores. São Paulo: Pólis, 1998.

GRIPPI, S. Lixo: Reciclagem e sua história. $2^{a}$ edição. Local: Interciência, 2006. p.5.

LAUBISCH, T. N. F. Resíduos sólidos: uma possível solução ecológica. Rio de Janeiro, 1990. Tese (Mestrado)-Programa de Engenharia de Produção da COPPE / UFRJ, Rio de Janeiro, 1990.

LEME, Francílio Paes. Engenharia de Saneamento Ambiental. Rio de Janeiro: LTC Livros Técnicos e Científicos, 1982.

LIMA, J. D., Gestão de resíduos sólidos urbanos no Brasil; Rio de Janeiro, RJ: ABES, 2001.

MAZETO, C. C; ABREU, P. E. Implantação da Coleta Seletiva em um Condomínio Residencial em Curitiba, Curitiba, 2014.

MINISTÉRIO DAS CIDADES. Disponível em: < http://www.cidades.gov.br/> Acessado em 27/03/2016.

MINISTÉRIO DO MEIO AMIENTE. Disponível em: < http://www.mma.gov.br/> Acessado em 27/03/2016.

MOTTA, Ronaldo Seroa da. O uso de instrumentos econômicos na gestão ambiental. Rio de Janeiro: IPEA, 2000.

MUCELIN, C. A; CUNHA, K.C; PEREIRA, J. O. Sistema de gerenciamento de resíduos sólidos para pequenas comunidades. 2000. Disponivel em < http://www.sanepar.com.br/sanepar/sanare/v15/sistgerpag48.html> Acessado dia $10 / 02 / 2016$.

OLIVEIRA, S. de - PASQUAL, A. Gestão de resíduos sólidos na microregião Serra de Botucatu/SP. Revista Limpeza Pública, São Paulo, n. 47 p.23-28, 1998. 
RODRIGUES, L. F; CAVINATTO, M. V. Lixo: de onde vem? Para onde vai? 2a edição. Local: Moderna, 2003. p.6

SEMINÁRIO INTERNACIONAL AS MELHORES PRÁTICAS EM GESTÃO INTEGRADA DE RESÍDUOS SÓLIDOS, 2003, Rio de Janeiro. Anais.... Rio de Janeiro - Secretaria de Estado de Meio Ambiente e Desenvolvimento Urbano, 2004.

SILVA, N. F. Saneamento Ambiental de Campos dos Goytacazes: um diagnóstico da invisibilidade que compromete a qualidade de vida. 2004. $101 \mathrm{f}$. Dissertação (Mestrado em Planejamento Regional e Gestão de Cidades). Universidade Candido Mendes, Campos dos Goytacazes, RJ. 